Supplement of Hydrol. Earth Syst. Sci., 21, 6307-6327, 2017

https://doi.org/10.5194/hess-21-6307-2017-supplement

(c) Author(s) 2017. This work is distributed under

the Creative Commons Attribution 3.0 License.

(c) (1)

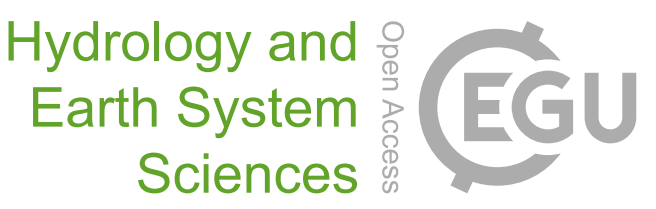

Supplement of

\title{
The 2010-2015 megadrought in central Chile: impacts on regional hydroclimate and vegetation
}

René D. Garreaud et al.

Correspondence to: René D. Garreaud (rgarreau@dgf.uchile.cl)

The copyright of individual parts of the supplement might differ from the CC BY 3.0 License. 


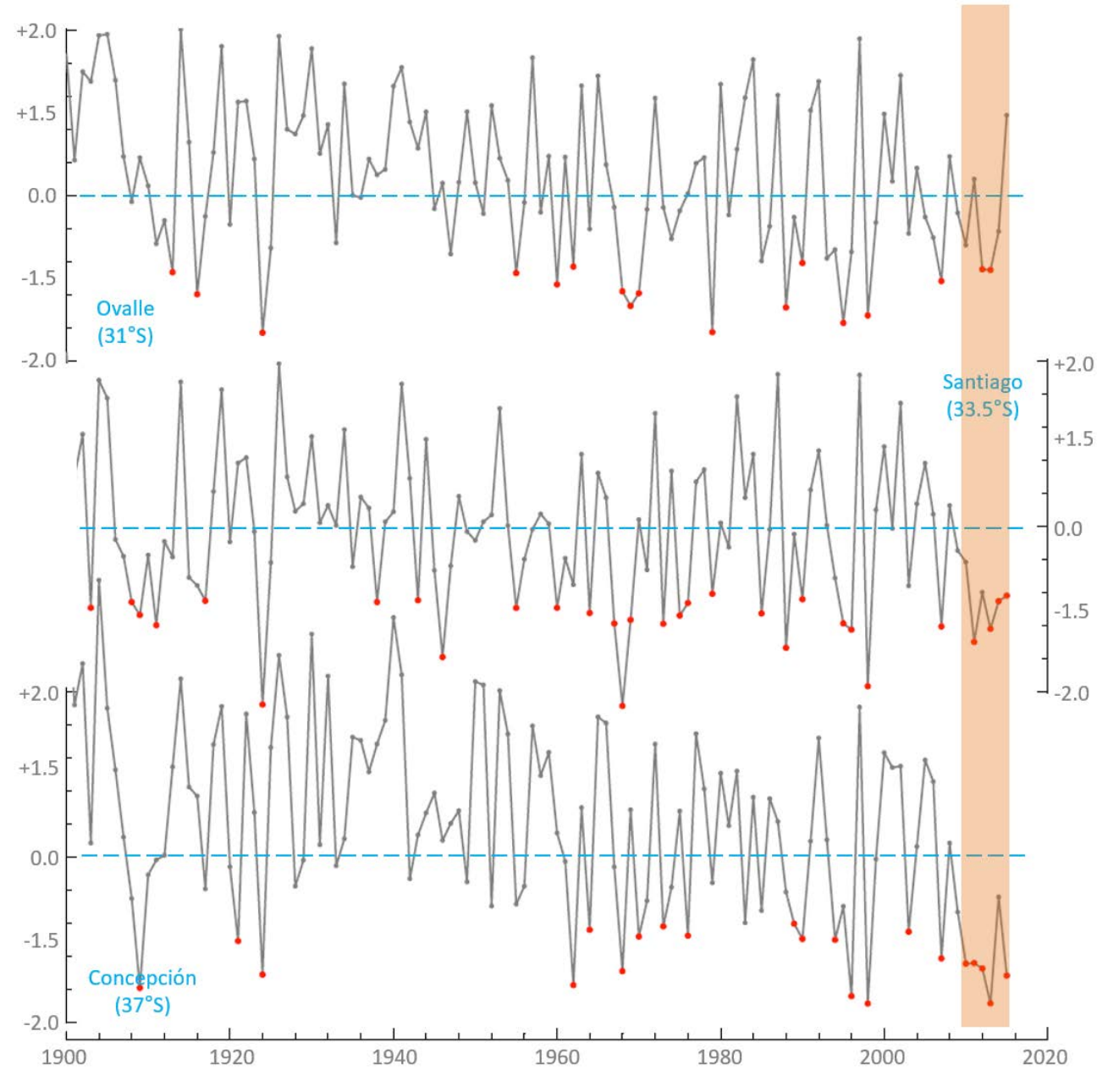

5

6 Figure S1. Standardized Precipitation Index (SPI) with 12-month time scale evaluated

7 in December of each year for stations Ovalle, Santiago and Concepción. The MD period

8 is indicated.

9 


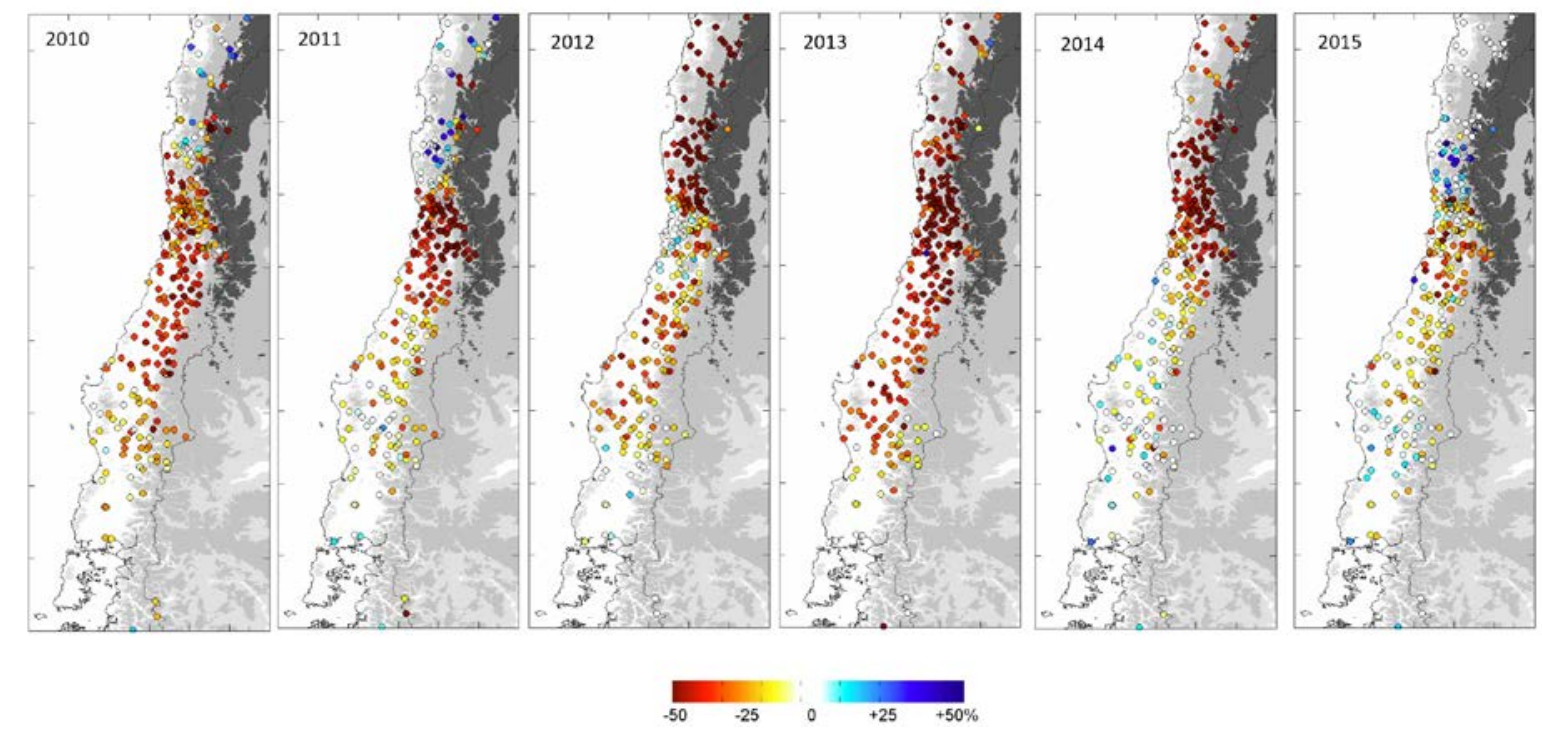

11 Figure S2. Annual rainfall anomalies (relative to the 1980-2010) for each year within

12 the MD.

13 

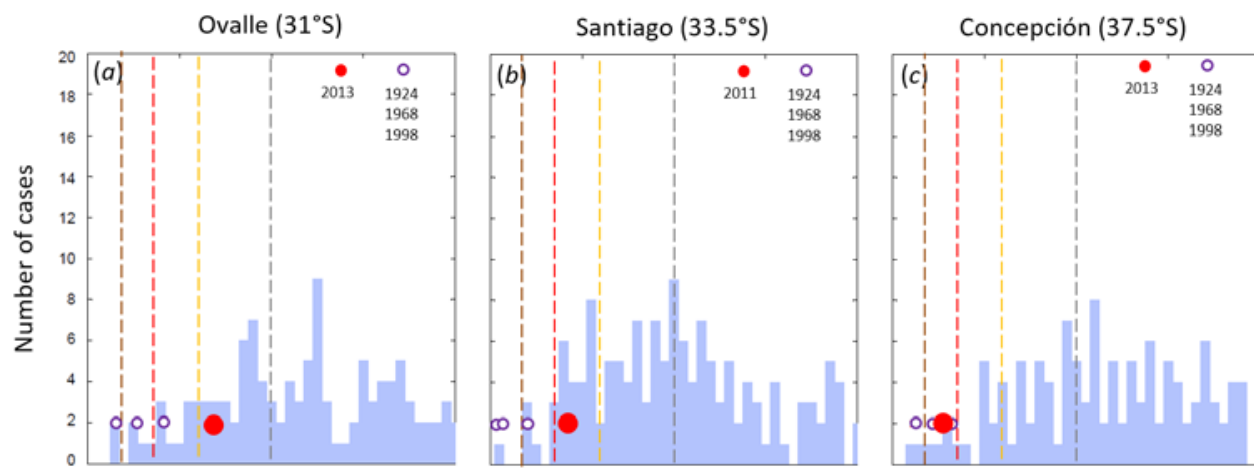

1-year
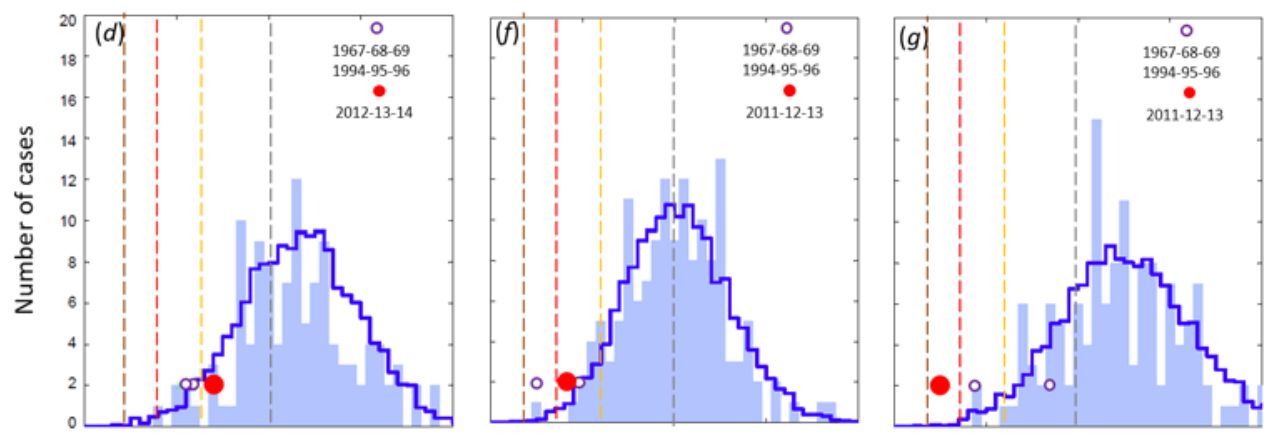

3-years

average
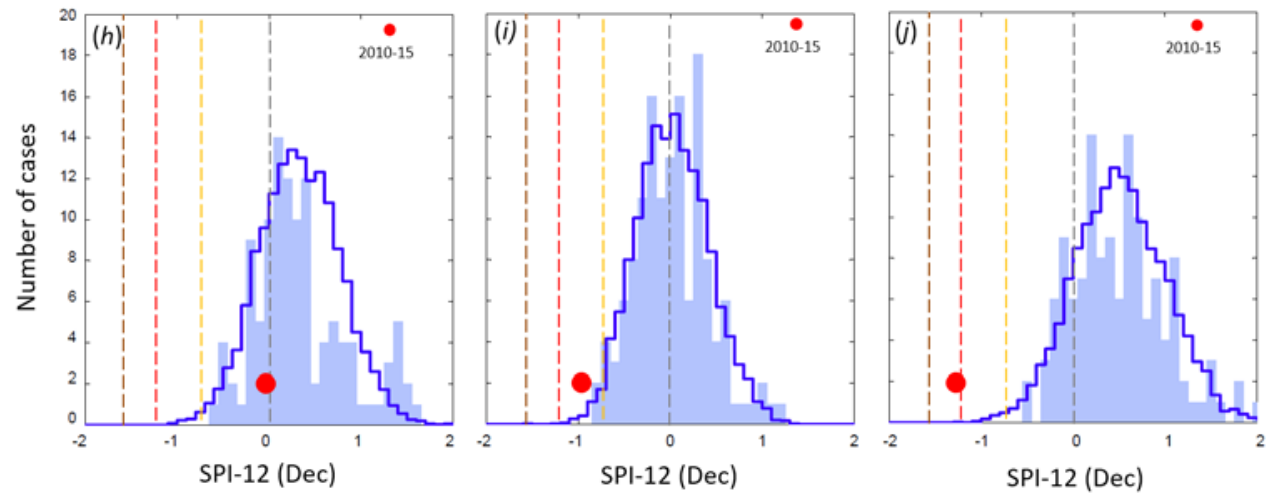

6-year

average

15 Figure S3. Upper panels: Histograms of the historical SPI-12D values (light blue bars;

16 1915-2009) for stations Ovalle, Santiago and Concepción. The red circle indicates the

17 worst year during the $\mathrm{MD}$, the smaller purple circles indicate the values in contemporaneous droughts. Middle and lower panels: as before but for 3-years and 6-

19 years average, respectively. The blue thick line is the distribution obtained from 5000

20 three-year periods formed by randomly selecting three/six years in the historical 21 period. 


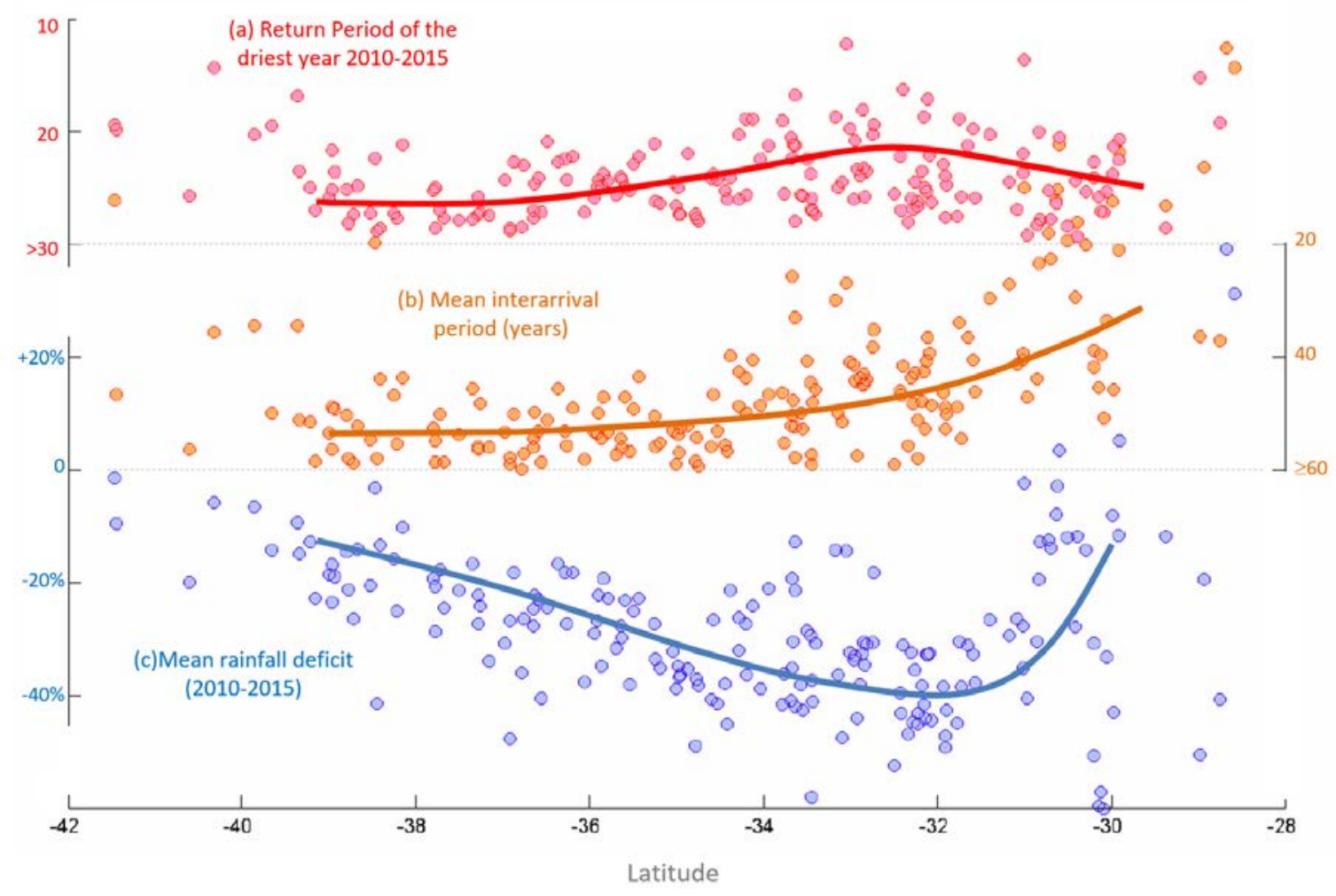

22

23

24

25

26

27

28

29

Figure S4. (a) Return period of the driest year within the MD (2010-2015) calculated

as the average recurrence interval within the historical period (1960-2009) in each station. (b) Mean interarrival period (in years) of a dry spell (sequence of years with rainfall deficit $>25 \%$ ) equal or longer than the current MD in each station. (c) Mean rainfall deficit during the MD (Jan. 2010 to Dec. 2015). The horizontal axis is the station latitude. 


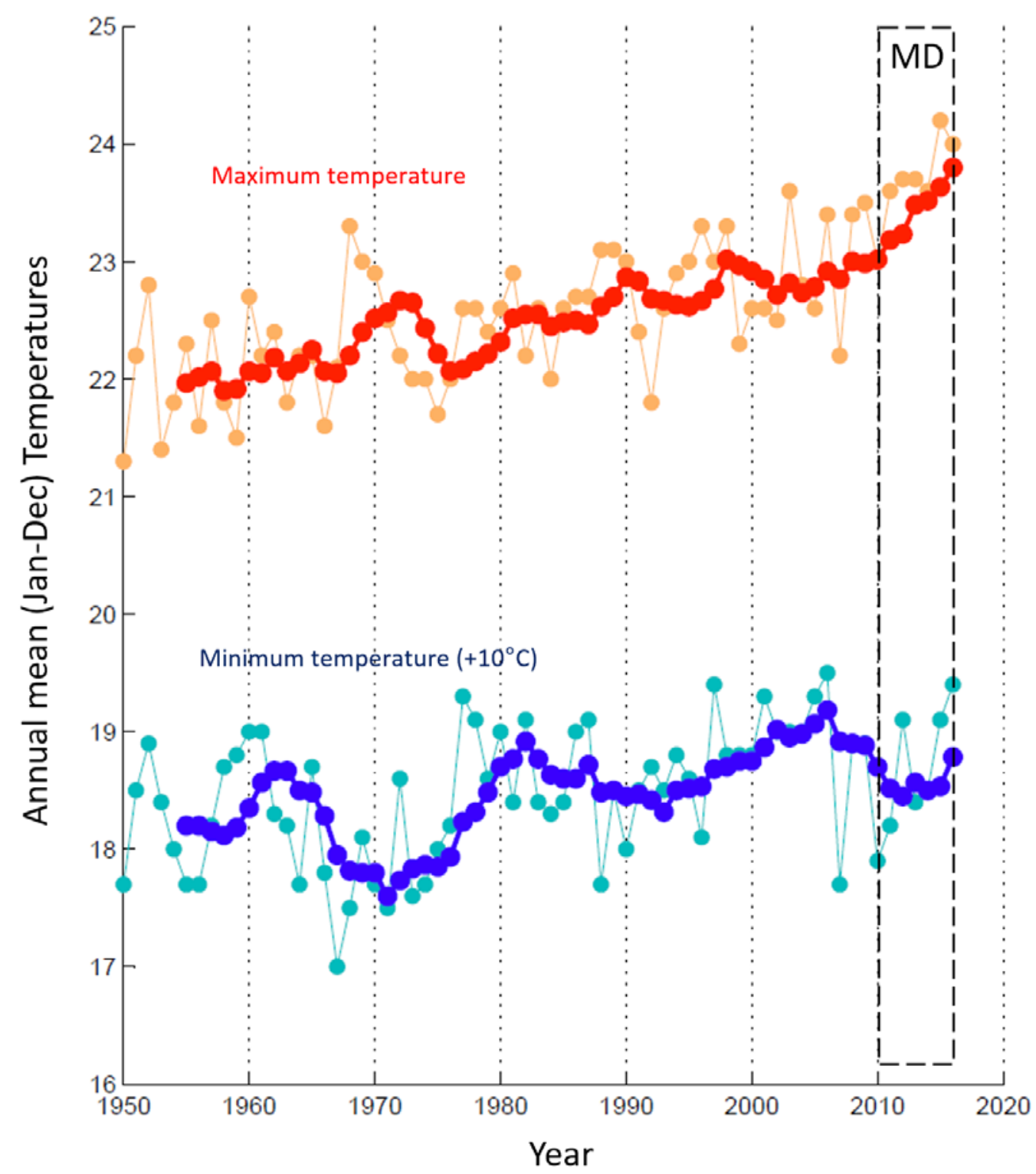

31 Figure S5. Annual mean (Jan-Dec) maximum (red and orange curves) and minimum

32 (blue and cyan curves) temperatures in station Quinta Normal (Santiago; $33.5^{\circ} \mathrm{S}$,

$\left.3370.4^{\circ} \mathrm{W}, 525 \mathrm{~m} \mathrm{ASL}\right)$. The thin lines are annual values. The thick lines are the average

34 of the last 6 years (the last data point is the average 2011-2016). The MD period is 35 indicated. 


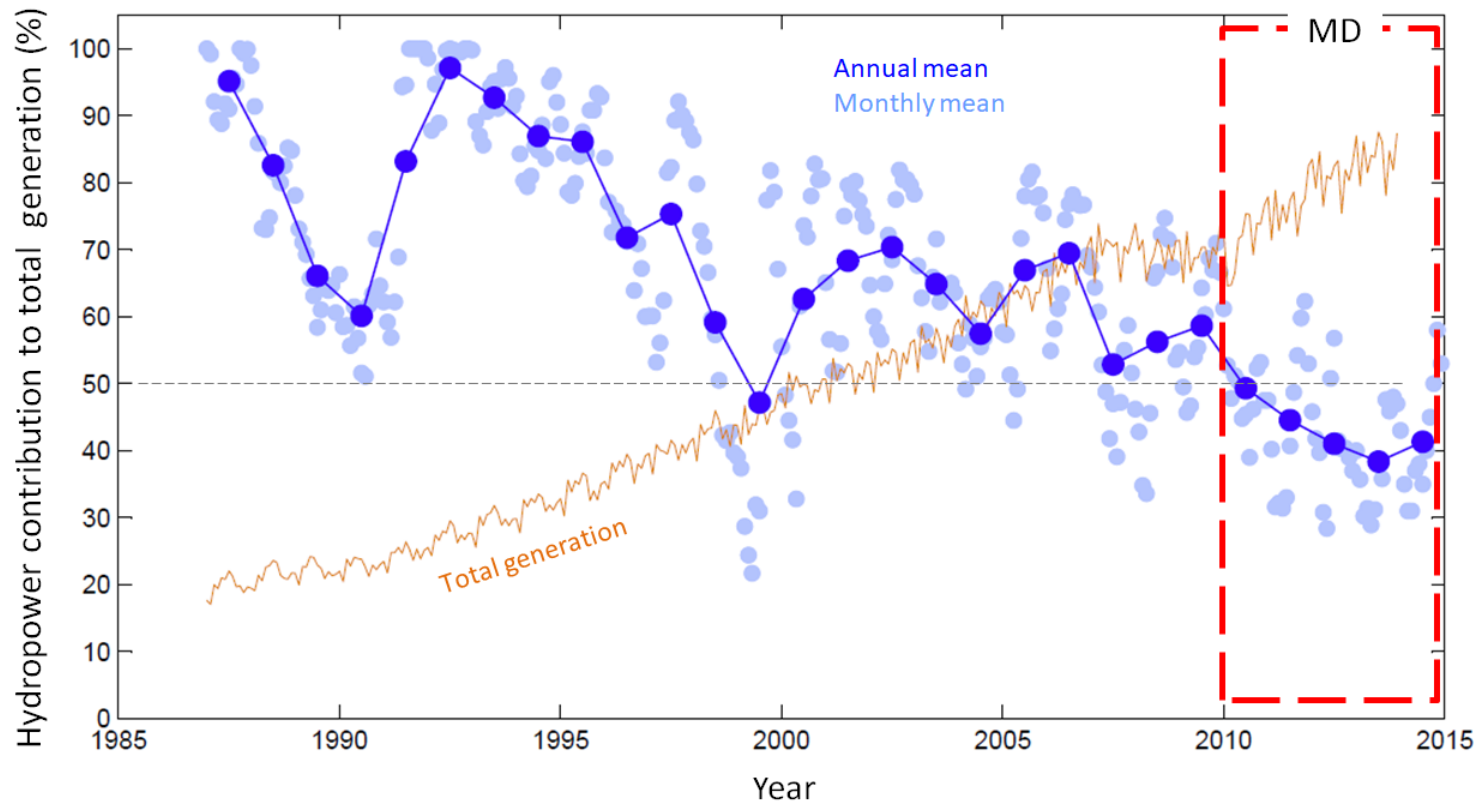

38

39 Figure S6. Fraction of the electrical energy in central Chile generated by hydropower

40 stations (blue lines and circles). For reference, it is also indicated the monthly mean

41 electrical energy generated in central Chile (orange line, 100\% represents 60.000

$42 \mathrm{GWh})$. 